\title{
Mobile Tax Base as a Global Common
}

\author{
Kai A. Konrad* \\ WZB and Free University of Berlin
}

August 31, 2007

\begin{abstract}
Countries try to attract -and tax-mobile resources such as foreign direct investment flows or human capital. Their activities include informative or persuasive advertising, branding, and educational policies that generate home attachment. This competition closely resembles the competition for a common pool resource. Further, Bertrand competition in tax rates interacts with this type of competition. I provide some piecemeal evidence on what activities countries use. I also endogenize the size of the group of loyal and non-loyal citizens or investors and consider the implications of tax harmonization and minimum taxes for these types of non-price competition. Home attachment reduces the intensity of tax competition, but generates a strategic disadvantage for the country that invests much in such home attachment. Harmonization of taxes and minimum taxes can intensify the common pool problem.
\end{abstract}

Keywords: tax competition, common pool, advertizing, nation brands, instilling preferences, home bias, patriotism.

JEL classification numbers: H77, F21, F22

${ }^{*}$ Correspondence address: Kai A. Konrad, Social Science Research Center Berlin (WZB), Reichpietschufer 50, D-10785 Berlin. Phone: +49-30-25491-402. Fax: +49-3025491-400. E-mail: kkonrad@wz-berlin.de. I thank Florian Morath for valuable comments. 


\section{Introduction}

Public finance has analyzed competition for direct investment, financial capital and human capital ${ }^{1}$ with a focus on tax rates as the instrument of competition. There are notable exceptions, but the general validity of the claim becomes evident if one recalls the Wildasin (1988) or the Zodrow-Mieskowski (1986) frameworks of tax competition that have become the workhorses for analysing tax competition. ${ }^{2}$ In this respect, much of this analysis is structurally similar to what would be considered as Bertrand or price competition in the context of the competition between firms. Other types of 'price' competition for capital have also been explored: standard auctions (Black and Hoyd 1989, Besley and Seabright 1999), monopolistic competition (Kind, Knarvik and Schjelderup 2000), Hotelling location competition (Hohaus, Konrad and Thum 1994, Justman, Thisse and van Ypersele 2002, 2005). Prices govern the allocation of resources also in these approaches.

Countries can use other means of competition by which they can try and acquire a larger share of the tax base, and some of these competition modes make the tax base a common pool resource. ${ }^{3}$ I define a common pool resource here as a resource that is rival in its use, for which property rights are not (yet) well defined, with players rivalling regarding the allocation of property rights. Tax rates or investment subsidies are clearly important determinants as variables that govern the allocation of the internationally mobile tax base. But the extent to which a country can impose taxes on a given tax base without making it move away is governed by activities which are structurally similar to appropriation effort or effort in establishing property claims. Major

\footnotetext{
${ }^{1}$ Foreign direct investment and financial capital are the more prominent targets in tax competition. However, competition for human capital has a long tradition. Bhagwati and Dellalfar (1973), Bhagwati (1976) and Raymond (1973) were among the first to discuss the downsides of this competition.

${ }^{2}$ Any list of seminal contributions to this capital tax competition literature will notoriously be unfair to some authors, but should include Zodrow and Mieszkowski (1986), Wilson (1986), Wildasin (1988), Gordon (1986, 1992) and Sinn (1990). I gladly leave a possible blame of omissions to the excellent surveys by Wilson (1999), Wildasin and Wilson (2004), Fuest, Huber and Mintz (2005) and Sørensen (2007).

${ }^{3}$ Tax base as a common pool resource has been considered in the context of vertical tax externalities, where a tax base in one location is subject to taxation by multiple, vertically ordered and independently acting fiscal authorities, as in Keen (1998), Keen and Kotsogiannis (2002) and Wrede $(1997,2000)$. Wrede (1999) explicitly uses the term "fiscal common" in this context.
} 
categories of such appropriation efforts are advertising, branding, and the investment in tax payer loyalty.

Countries widely advertise, trying to attract foreign direct investors. This advertising is partially informative. Informative advertising was used in Austria's campaign in 2005. The full-page advertisement simply displayed a comparison between the corporate tax rates of 25 percent in Austria and 38 percent in Germany. The advertisement also emphasized that Austria and Germany are very similar along other dimensions that are relevant determinants for investment decisions, including access to the German market. ${ }^{4}$

ADVERTISEMENT

\section{A Lesson for Those Who Want to Invest in the German Market - but not in German Taxes.}

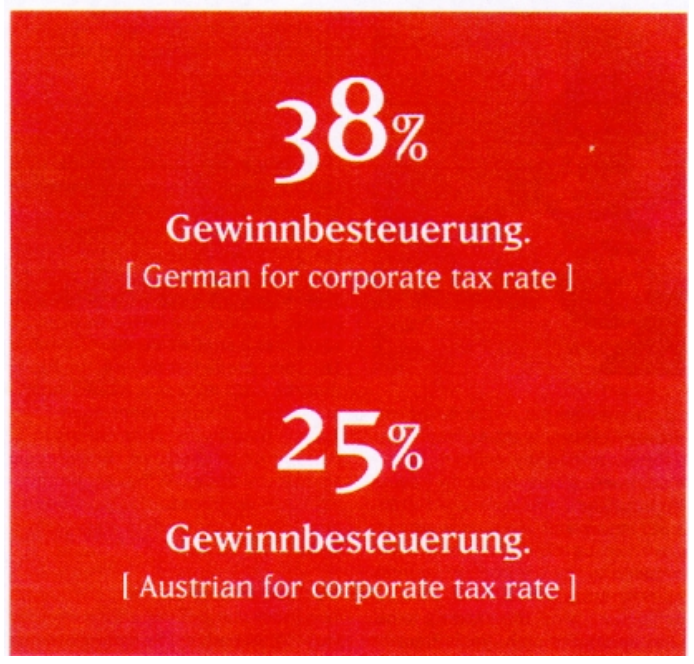

This type of advertisement weakens the loyalty of citizens or investors in other countries, by informing them about other alternatives. Other types of advertising may aim at building up a particular image, making the country different from other countries in the eyes of the investors or tax payers. An example for this type of advertising is a recent campaign ${ }^{5}$ by the International Marketing Council (IMC) of South Africa by which a public-private

\footnotetext{
${ }^{4}$ See The Economist, 2005, 3-5/05.

${ }^{5}$ See, e.g., The Economist, October 21, 2006, September 30, 2006.
} 
partnership tries to give the country the image described on their homepage: „South Africa, a country at the southern tip of Africa, inspires the world to a new way of doing things, because our unique combinations create refreshing possibilities".

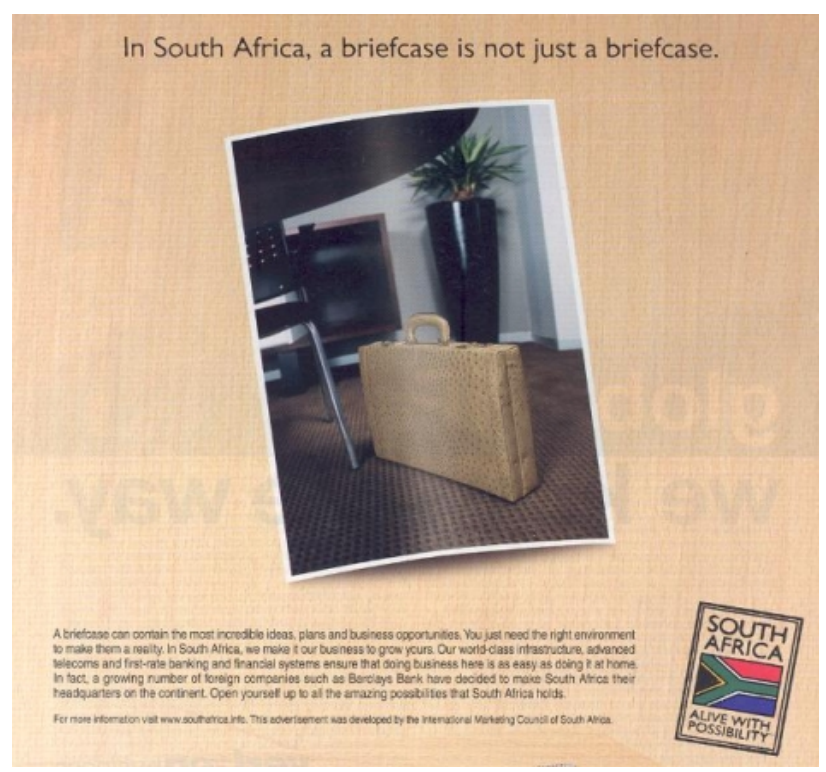

Finally, Germany launched a major advertising campaign for attracting foreign direct investment in 2006, labelled Germany, Land of Ideas. As part of this campaign, German fashion top model Claudia Schiffer volunteered to pose. Pictures of her have been displayed prominently on advertising boards in the subway stations of London and New York. On these pictures she is partially wrapped in a German flag and the headline says: "Invest in Germany, boys". ${ }^{6}$

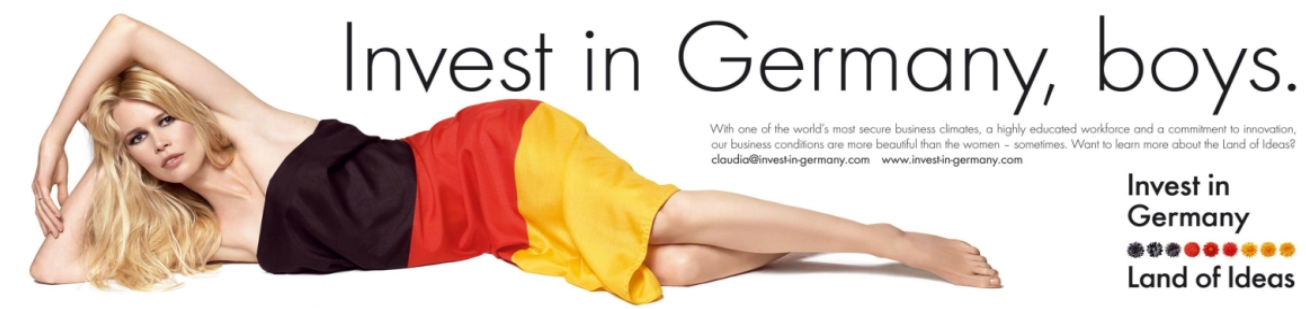

\footnotetext{
${ }^{6}$ http://www.land-der-ideen.de/CDA/presse_medien,33,0,dde.html
} 
The idea that "persuasive" advertising is a common pool problem where firms expend effort for attracting a larger share in a given pool of customers is very old. It is the basic underlying hypothesis for much of the formal game theory on advertising in the business literature and can be traced back at least to Friedman (1958) or Schmalensee (1976). Countries play these games as well. ${ }^{7}$

Much like firms, countries also invest in their brand names. The Anholt Nation Brands Index, for instance, publicizes the brand values of 30 major nations on a quarterly basis. According to this index, in 2006 the brand value of the United States of America was more than 17 trillion US-Dollar. The value of Germany as a brand was lower, but still 100 times the market value of Coca-Cola. The factors that influence the brand value are partially known. A nation's relative success along many dimensions, including economics, science or sports matters. Also, public attention gained from hosting major events such as the Olympics or the World Soccer Championships matter. Expenditure by which politicians try to persuade the members of the IOC, or expenditure that promote national sports programmes can be seen as marketing expenditure or investment in the nation brand.

Similar to firms, countries also try to build up what would be called a "base of loyal customers" in business language. Countries may try to make citizens, tax payers or the tax base immobile. Along this dimension, countries may have even more powerful instruments than firms. Social security systems and the payment structure for civil servants are, for instance, ways to generate a lock-in for some share of the population. Countries also choose or strongly influence the content of primary and secondary education. They can and do use this to instill patriotism as a particular type of emotional home attachment. Many examples for this type of policy can be given. The prototype of education policy could be observed in Nazi-Germany which very actively pursued an education policy with rather extreme goals. This example also shows that this is a very powerful instrument, and one that is rather unappealing. But more moderate versions of loyalty building education with a clear shift in intentions can be traced in virtually all countries even today. The American Boy Scouts, like many other youth organizations, explicitly

\footnotetext{
${ }^{7}$ Similarly, when politicians travel, they advertize national firms and their products, but also promote their countries for attracting investors. While such activities are difficult to measure, Rose (2007), for instance, documents that the foreign service heavily engages in trade policy.
} 
mention patriotism as one of their educational goals. ${ }^{8}$ Japan just passed a bill according to which patriotism is a declared goal of the compulsory educational system and similar developments emerged recently in Poland where 'patriotism' was discussed as a possible subject to be learned at school.

In what follows I consider effort of this third type: investment in the loyalty of citizens and tax payers. ${ }^{9}$ I leave it open what instruments are used when pursuing these goals, but assume that the application of these means is costly. I will first allow for countries using both modes of competition: investments in loyalty of citizens, followed by price competition in terms of setting tax rates. I will then restrict tax competition by way of a minimum tax and by tax harmonization.

The option to use instruments that increase tax payers' loyalty may explain why a general downward trend in tax rates has only partially been observed. ${ }^{10}$ The low pressure on tax rates may have a partial explanation in such activities that moderate what would otherwise be a cut-throat competition.

Loyalty investment, advertising and nation branding has not been the subject of tax-competition theory, but the analysis of competition for tax base or mobile capital as a common pool problem has a number of precursors who focused on public expenditure on public goods or infrastructure as the means of non-price competition. Taylor (1992) considers jurisdictions which compete for foreign direct investment in a race regarding their speed of infrastructure investment. Menezes (2003), applying auction theory to this type of fiscal competition considers several variants of auctions, including

\footnotetext{
${ }^{8}$ Their official aims are stated in their federal charta of June 15, 1916: „...to teach them patriotism, courage, self-reliance, and kindred virtues, using the methods which are now in common use by Boy Scouts."

${ }^{9}$ The role of home attachment has received attention in the literature on decentralized decision making in federations (e.g., Mansoorian and Myers 1993) and in the context of tax competition (e.g., Andersson and Konrad 2003, Ogura 2006).

${ }^{10}$ Investors react to taxes. This is well documented by now, starting with early work by Hartman (1984) and surveyed and evaluated in a meta-study by De Mooij and Ederveen (2003). However, the literature seemingly fails to come up with unanimous evidence on a general downward trend of the fiscal burden (see, e.g., Devereux, Griffith and Klemm 2002). Stewart and Webb 2006, p. 191) draw an even more striking conclusion: "Corporations are undoubtedly sensitive to taxation, just as homeowners are sensitive to property taxes. Yet this sensitivity does not give rise to a race to the bottom in corporate taxation any more than it does to property taxes. The fact that Altshuler and Goodspeed find no evidence of any intensification of strategic interaction in capital taxation policies during the post 1980 globalization era is entirely consistent with our results."
} 
an all-pay auction that involves public investment expenditure at multiple locations and causes wasteful duplication of public infrastructure. Jayet and Paty (2006) consider a similar problem when jurisdictions decide whether or not to build up the infrastructure for a business area, hoping to win or attract lumpy investment. The same type of overinvestment problem is less immediately obvious in a framework with smooth capital flows as in Keen and Marchand (1997). They also find that public expenditure on infrastructure inputs may be excessive, in particular, compared to their alternative use for public consumption goods. ${ }^{11}$ Also Sinn's (1997) critical assessment of the functioning of systems competition, particularly the provision of public infrastructure goods in the context of tax competition hints at this problem. These approaches essentially consider the problem of attracting desirable investment as a rent-seeking, or contest problem. Excessive infrastructure expenditure may occur due to several reasons. First, regions or countries may invest and sometimes fail to attract investment, due to the lumpiness of investment projects. Second, even if the allocation of desirable investment is a smooth function of public infrastructure investment, competition directs too much resources into infrastructure competition, compared to its alternative use.

Structurally the analysis uses results from Bertrand competition with shares of loyal 'customers', as in Narasimhan (1988) and Deneckere, Kovenock and Lee (1992), but endogenizes the choice of the set of 'loyal customers', with governments competing for tax revenues from their citizens taking the roles of firms competing for sales revenues from their customers. ${ }^{12}$ A paper that considers formally the endogeneity of the sets of loyal customers is Roy (2000). He considers firms' decisions to advertise their existence to different sets of potential customers. If a customer knows one firm only, he buys from

\footnotetext{
${ }^{11}$ Several researchers took up this type of competition. Bucovetsky (2005) considers infrastructure investment in a context with agglomeration. Benassy-Quere, Gobalraja and Trannoy (2007) allow for both tax competition and public input competition. Wildasin (1988) and Wilson (2005) consider the role of expenditure competition. Matsumoto (2000) adds labor mobility and Matsumoto (2004) disaggregates public inputs into inputs that are complementary to the mobile factor or to the immobile factor of production in this context. Wehke (2006) analyses how coordination on taxes will affect this second channel of competition.

${ }^{12}$ Formally the analysis is closely related to the literature that take their departure from Varian's (1980) "model of sales". See, in particular, Narasimhan (1988), Deneckere, Kovenock and Lee (1992) and Baye, Kovenock and de Vries (1992), and Baye and Morgan and Scholten (2007) for an overview.
} 
this firm for any price lower than his reservation price. If the consumer knows both firms, this makes him perfectly price sensitive. If he knows none of the firms, he does not buy at all. Advertising in this framework may generate or destroy loyalty, depending on whether advertising informs a customer who already knows another firm or not. This type of investment in loyalty has its counterpart in the context of countries' advertising policy as well. It differs, however, from the type of investment I will consider, by which countries may expose their citizens to an activity that may instill a home attachment in a subgroup of the population.

I proceed as follows. In section 2 I adapt Narasimhan's analysis of price competition with loyal customers to the contest of countries' competition. In section 3 I consider endogenous choices regarding the policy to instill home attachment. Sections 4 and 5 consider minimum taxes and harmonized taxes as possible constraints on the tax rates that countries can choose and how they affect the countries' investment in loyalty. Section 6 concludes.

\section{Tax competition with loyal tax payers}

Consider two countries, $A$ and $B$. In each country there is a set of initial residents, described by an interval of length 1 . They can be firms, firm owners who may move with their firms, or individuals with human capital, and I will refer to them either as "citizens" or "tax payers". The joint set is the "common pool". In stage 1 the governments $i \in\{A, B\}$ choose how large a set $n_{i} \in\{0, n\}$ with $0<n<1$ of their initial residents should be made "loyal", i.e., turned into tax payers with strong home attachment. The cost of these policies are $C_{i}(0)=0$ and $C_{i}(n)=c_{i}>0$. The set of individuals of size $2-n_{A}-n_{B}$ remains mobile. The governments maximize their tax revenues, net of investment cost. ${ }^{13}$ They choose per-head taxes $t_{A}$ and $t_{B}$ from the interval $[0, r]$ with $r$ a finite, exogenously given maximum tax. This choice constitutes stage 2 .

In stage 3 individuals react to the taxes. They choose their country of residence and pay taxes. Loyal citizens are attached to their country. They simply pay the tax that applies in their country. Non-loyal citizens are

\footnotetext{
${ }^{13}$ This objective function is compatible with a Leviathan view of government as well as with a welfarist government whichgives capital owners a low weight in its welfare function, or has a sufficiently high shadow price of public funds, for instance, because it places sufficient weight on redistribution.
} 
perfectly and costlessly mobile and locate in the country with lower taxes. If both countries have the same tax, they locate in each country with the same probability. Depending on $\left(n_{A}, n_{B}, t_{A}, t_{B}\right)$, country $A$ 's tax revenues are

$$
T_{A}(\mathbf{n}, \mathbf{t})=\left\{\begin{array}{ccc}
n_{A} t_{A} & \text { if } t_{A}>t_{B} \\
\left(1+\frac{n_{A}-n_{B}}{2}\right) t_{A} & \text { if } t_{A}=t_{B} \\
\left(2-n_{B}\right) t_{A} & \text { if } t_{A}<t_{B}
\end{array}\right.
$$

and analogously for $B$. Note that (1) implicitly defines a tie-breaking rule: the tax base $2-n_{A}-n_{B}$ that is not home-attached has an equal chance to locate in each of the countries. ${ }^{14}$ Taking also into consideration the cost of $n_{i}$, the payoffs can be stated as

$$
\pi_{i}(\mathbf{n}, \mathbf{t})=T_{i}(\mathbf{n}, \mathbf{t})-C_{i}\left(n_{i}\right)
$$

The payoffs in the taxation subgame are structurally equivalent to the profits in Narasimhan's (1988) price leadership game with loyal customers and simultaneous choices of prices. Note that this game has no equilibrium in pure strategies if $\max \left\{n_{A}, n_{B}\right\}>0$. A proof is by contradiction. ${ }^{15}$ Narasimhan shows that this game has a unique subgame perfect equilibrium for given $n_{B} \geq n_{A}$ in mixed strategies that are described by the following cumulative distribution functions:

$$
F_{A}\left(t_{A}\right)=1+\frac{n_{B}}{2-n_{A}-n_{B}}-\frac{n_{B} r}{\left(2-n_{A}-n_{B}\right) t_{A}} \text { for } t_{A} \in\left(\frac{n_{B} r}{2-n_{A}}, r\right)
$$

and with $F_{A}\left(t_{A}\right)=0$ for $t_{A}<\frac{n_{B} r}{2-n_{A}}$ and $F_{A}\left(t_{A}\right)=1$ for $t_{A} \geq r$, and

$F_{B}\left(t_{B}\right)=1+\frac{n_{A}}{2-n_{A}-n_{B}}-\frac{\left(2-n_{B}\right)}{\left(2-n_{A}\right)} \frac{n_{B} r}{\left(2-n_{A}-n_{B}\right) t_{B}}$ for $t_{B} \in\left(\frac{n_{B} r}{2-n_{A}}, r\right)$

with $F_{B}\left(t_{B}\right)=0$ for $t_{B}<\frac{n_{B} r}{2-n_{A}}$ and $F_{B}\left(t_{B}\right)=1$ for $t_{B} \geq r$. Note that $F_{B}$ dominates $F_{A}$ in the sense of first-order stochastic dominance. Both

\footnotetext{
${ }^{14}$ I make this assumption throughout, in order to avoid optimization problems on open sets.

${ }^{15}$ Let $n_{B}=n$. Suppose $\left(t_{A}, t_{B}\right)$ is an equilibrium. Then $t_{B}>0$, as $t_{B} n>0$. Let $t_{A}=t_{B}>0$. Then $t_{A}$ is not an optimal reply to $t_{B}$. For instance, $t_{A}=t_{B}-\epsilon$ for sufficiently small positive $\epsilon$ yields higher tax revenue for $A$. Let $t_{A}=t_{B}+\delta$ for a given finite positive $\delta$. Then $t_{B}$ is not an optimal reply to $t_{A}$, as $t_{B}=t_{A}-\epsilon$ for sufficiently small $\epsilon$ yields higher tax revenue. Similarly for $t_{B}=t_{A}+\delta$ and player $A$.
} 
distributions have the same support, but $F_{B}(t) \leq F_{A}(t)$ for all $t \in\left(\frac{n_{B} r}{2-n_{A}}, r\right]$. Moreover, only $F_{B}$ may possibly have a mass point and this mass point is at $t_{B}=r$.

The payoffs as functions of the own tax choice that emerge from these mixed strategies can be obtained by inserting them into the payoff function (2) as

$$
\begin{aligned}
\pi_{A}\left(t_{A}\right) & =F_{B}\left(t_{A}\right) n_{A} t_{A}+\left(1-F_{B}\left(t_{A}\right)\right)\left(2-n_{B}\right) t_{A}-C_{A}\left(n_{A}\right) \\
& =\frac{\left(2-n_{B}\right)}{\left(2-n_{A}\right)} n_{B} r-C_{A}\left(n_{A}\right)
\end{aligned}
$$

and

$$
\begin{aligned}
\pi_{B}\left(t_{B}\right) & =F_{A}\left(t_{B}\right) n_{B} t_{B}+\left(1-F_{A}\left(t_{B}\right)\right)\left(2-n_{A}\right) t_{B}-C_{B}\left(n_{B}\right) \\
& =n_{B} r-C_{B}\left(n_{B}\right)
\end{aligned}
$$

for all $t_{A} \in\left[\frac{n_{B} r}{2-n_{A}}, r\right)$ and $t_{B} \in\left[\frac{n_{B} r}{2-n_{A}}, r\right]$ and smaller than this equilibrium payoff for tax choices from outside this interval. This shows why these mixed strategies constitute optimal replies to each other and proves that (3) and (4) constitute an equilibrium at stage 2. Deneckere, Kovenock and Lee (1992) provide more intuition on this result. By definition, country $B$ has more loyal citizens than country $A$. The country benefits from having more loyal citizens if it attracts and taxes only this group. This advantage turns into a disadvantage in the strategic tax competition game. Each country gains the same additional tax base $2-n_{A}-n_{B}$ by undercutting the other country. Country $B$ has higher cost of undercutting A than vice-versa, as $B$ has the larger set of loyal citizens who pay $B$ 's tax in any case. Because of this disadvantage, country $\mathrm{B}$ has an equilibrium payoff that is equal to $r n_{B}$. This is the minimum amount of taxes which $B$ can obtain, irrespective of $t_{A}$, and is called the stand-alone payoff of country $B$. Summarizing, the finding is

Proposition 1 (Narasimhan 1988) Let $n_{A} \leq n_{B}$. Then the tax competition equilibrium with simultaneous choices of tax rates is characterized by mixed strategies (3) and (4) and payoffs

$$
\pi_{A}^{*}=\frac{\left(2-n_{B}\right)}{\left(2-n_{A}\right)} n_{B} r-C_{A}\left(n_{A}\right) \text { and } \pi_{B}^{*}=n_{B} r-C_{B}\left(n_{B}\right)
$$

Note that the country with more loyal tax payers receives an expected tax revenue that is equal to the revenue from taxing the loyal tax payers 
only. If both countries have chosen to invest in loyal tax payers, due to the symmetry in the size of these groups, both countries end up with tax revenue $T_{i}=n r$. If country $A$ has chosen $n_{A}=0$, then this country also benefits from the group of patriots in country $B$. This can be seen from (9) as $\pi_{A}^{*}$ is increasing in $n_{B}$.

The equilibrium has interesting comparative static properties. First consider taxation and tax revenue.

Proposition 2 (Baye, Kovenock and de Vries 1992) The country with the larger group of loyal citizens chooses higher expected taxes.

Proof. Use of $n_{B}=n$ and $n_{A}=0$ yields

$$
E t_{B}=\int_{t=\frac{n r}{2}}^{t=r} t d F_{B} \text { and } E t_{A}=\int_{t=\frac{n r}{2}}^{t=r} t d F_{A}
$$

respectively. However, $F_{A}\left(t_{A}\right) \geq F_{B}\left(t_{B}\right)$, i.e., $F_{B}$ dominates $F_{A}$ in the sense of first-order stochastic dominance. By Theorem 1 by Hadar and Russell (1969) this implies that $E t_{B} \geq E t_{A}$.

Countries which have a larger group of loyal citizens may charge higher taxes in the equilibrium in expectation. For this outcome the particular reason for citizens' loyalty does not need to be specified. Patriotism and other reasons of emotional attachment to one's home country serve similarly as language barriers or institutionally created barriers to migration such as travel restrictions or closed and strictly guarded borders. A key assumption for this result is, of course, that the government aims at high tax revenue. But this is an assumption which is justified both for countries with policy failure and a Leviathan government and for welfarist countries in which the tax proceeds are used to finance subsistence for a group of (completely immobile and) very poor citizens, and for which the group of citizens considered here is the target group for raising revenues for redistributional purposes.

Empirically, one should observe, for instance, that countries with closed borders, isolated countries, and countries with an overwhelmingly patriotic population may charge higher taxes. Indeed, as is shown in Kessing and Konrad (2007), across countries there is a positive and significant relationship between the level of patriotism and the level of income taxation.

A further comparative static problem relates to the size of the group of citizens who can be made immobile, for instance, by instilling patriotism or 
by other means. Globalization may be seen as a process that either increases the cost of turning citizens into loyal citizens, or as a process that reduces the set of people who could be made loyal. The cost effect will be considered later. The effect that makes the set of potentially loyal citizens smaller is as follows:

Proposition 3 An increase in $n$ increases the equilibrium tax revenues for all situations with $\max \left\{n_{A}, n_{B}\right\}=n$.

Proof. Consider the payoffs in (9) for the case with $n_{A}=n_{B}=n$. In this case $E T_{A}^{*}=E T_{B}^{*}=n r$, and this is increasing in $n$. For $n_{A}=0$ and $n_{B}=n$, we have $E T_{A}^{*}=\frac{2-n}{2} n r$, and

$$
\frac{\partial\left(E T_{A}^{*}\right)}{\partial n}=\frac{\partial\left(\frac{2-n}{2} n r\right)}{\partial n}=(1-n) r>0
$$

Further,

$$
\frac{\partial\left(E T_{B}^{*}\right)}{\partial n}=\frac{\partial(n r)}{\partial n}=r>0
$$

\section{Instilling loyalty}

Firms build up brands, make customers acquainted to these brands by means of advertising and other marketing means, including the attempt to build up customer relationships with the influx of new customers. Nations seemingly pursue similar strategies. They advertise the characteristics of their countries in newspapers, use other channels for building up relationships with investors or with citizens with much human capital, and may use their influence on primary and secondary education to instill home attachment. This shows that loyalty $n_{i}$ as defined in section 2 is endogenous.

Roy (2000) considered marketing investment by which firms can invest resources to make firms' product price known to subsets of a given set of customers. "Being known" in his context means that these customers will hear about this firm's product price, once this is chosen later on. This type of competition may also apply for tax competition. However, I will focus here on marketing and advertising that is used to build up brand value and reputation towards their own citizens and capital owners and make their own 
citizens "loyal". I restrict this choice of $n_{i}$ to $n_{i} \in\{0, n\}$. A country either invests in loyal citizens, or it does not.

Consider the payoffs from the different combinations of actions as in the matrix below.

\begin{tabular}{|c|c|c|}
\hline & $n_{B}=0$ & $n_{B}=n$ \\
\hline$n_{A}=0$ & $\pi_{A}=0$ & $\pi_{A}=\frac{2-n}{2} n r$ \\
& $\pi_{B}=0$ & $\pi_{B}=n r-c_{B}$ \\
\hline$n_{A}=n$ & $\pi_{A}=n r-c_{A}$ & $\pi_{A}=n r-c_{A}$ \\
& $\pi_{B}=\frac{2-n}{2} n r$ & $\pi_{B}=n r-c_{B}$ \\
\hline
\end{tabular}

It leads to the following properties of optimal investment in stage 1:

Proposition 4 If $c_{i} \in\left[0, \frac{n}{2} n r\right)$ then it is optimal for country $i$ to invest in loyalty. If $c_{i}>n r$, then $i$ does not invest in the loyalty of its citizens. If $c_{i} \in\left[\frac{n}{2} n r, n r\right]$ then it is optimal for country $i$ to invest (not invest) in loyalty if the other country does not invest (invests) in loyalty.

Proof. Consider country $i$. Let $q_{j}$ be the probability that the other country $j$ invests. Then the payoff of country $i$ is equal to $\left(1-q_{j}\right) \cdot 0+q_{j}\left(\frac{2-n}{2} n r\right)$ if $i$ does not invest, and equal to $\left(1-q_{j}\right)\left(n r-c_{i}\right)+q_{j}\left(n r-c_{i}\right)=\left(n r-c_{i}\right)$ if $i$ invests. Country $i$ invests if $n r-c_{i}>q_{j}\left(\frac{2-n}{2} n r\right)$, or $q_{j}<\frac{2}{(2-n)}\left(1-\frac{c_{i}}{n r}\right)$. As $q_{j} \geq 0$, this shows that $n_{i} \equiv 0$ for $c_{i}>n r$. Also, if $c_{i}<\frac{1}{2} n^{2} r$, as $q_{j} \geq 0$, this implies that $n_{i} \equiv n$ for $c_{i}<\frac{1}{2} n^{2} r$. Finally, if $c_{i} \in\left[\frac{n}{2} n r, n r\right]$ for both countries, $q_{A}=0$ and $q_{B}=1$ and $q_{A}=1$ and $q_{B}=0$ are optimal replies to each other. But also $q_{A}=2 \frac{n r-c_{B}}{(2-n) n r}$ and $q_{B}=2 \frac{n r-c_{A}}{(2-n) n r}$ are optimal replies to each other for this range of costs, as $q_{A}=2 \frac{n r-c_{B}}{(2-n) n r}$ makes $B$ indifferent whether to invest or not, and $q_{B}=2 \frac{n r-c_{A}}{(2-n) n r}$ makes $B$ indifferent about whether to invest or not.

The characterization of optimal replies can be used to describe the investment equilibria for different ranges of investment cost as in the nine areas in Figure 1. At very low and very high values of $c_{A}$ and $c_{B}$ both countries have dominant strategies. These are the areas in the corners (Northwest, Northeast, Southeast, Southwest) in the matrix in Figure 1. For instance, if both countries have a very small cost of loyalty investment, they both invest, such that $n_{A}=n_{B}=n$. If only one of the countries has a dominant strategy, this strategy choice induces a choice for the other country. The respective 


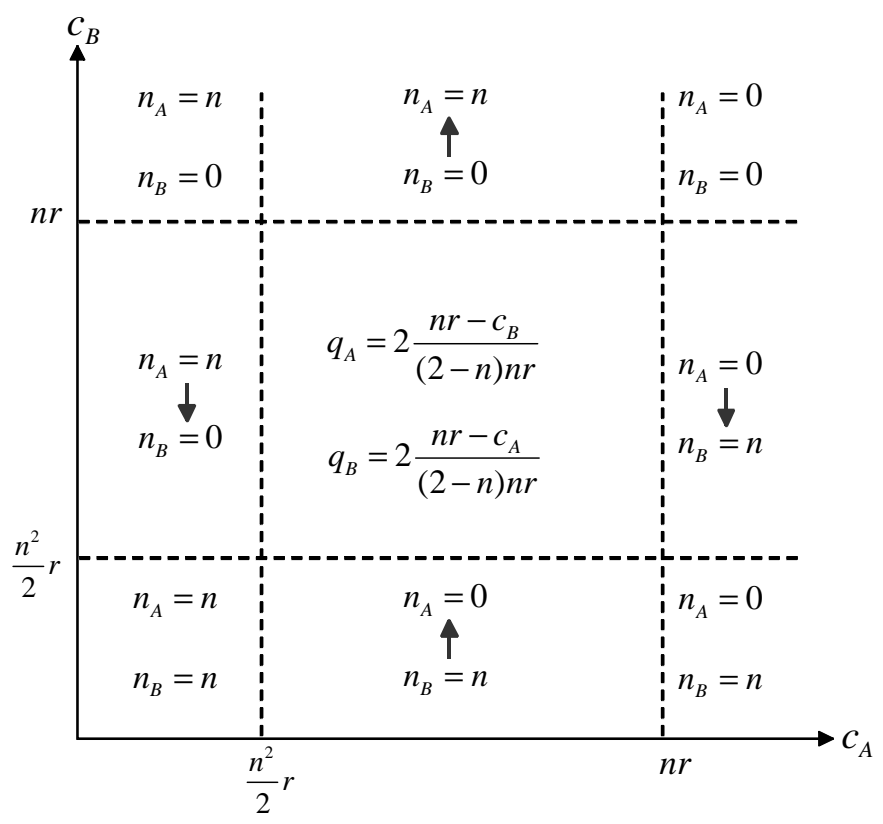

Figure 1: Equilibrium investment in loyal tax payers for different combinations of $c_{A}$ and $c_{B}$.

areas are in the South, North, East and West of Figure 1. If both countries have an investment cost in the intermediate range $c_{i} \in\left[\frac{n}{2} n r, n r\right]$, then both $\left(q_{A}=0 ; q_{B}=1\right)$ and $\left(q_{A}=1 ; q_{B}=0\right)$ are mutually optimal replies. However, there is also an equilibrium in mixed strategies with $q_{A}=2 \frac{n r-c_{B}}{(2-n) n r}$ and $q_{B}=2 \frac{n r-c_{A}}{(2-n) n r}$ in this case. These combinations occur in the center of the matrix in Figure 1. For this mixed strategy equilibrium the values of $q_{A}$ and $q_{B}$ are both increasing in $n$. If the technology of making citizens loyal becomes more effective in terms of the same amount of cost making a larger share of the own population loyal, then such an investment becomes more valuable for the country:

$$
\frac{\partial\left(2 \frac{n r-c_{i}}{(2-n) n r}\right)}{\partial n}=2 \frac{n^{2} r-2 n c_{i}+2 c_{i}}{n^{2}(2-n)^{2} r}>0 .
$$

Both the numerator and the denominator are strictly positive for $n \in(0,1)$ for $c_{i} \in\left(\frac{n}{2} n r, n r\right)$. In order to counterbalance the increased incentive to 
invest and to make a country $B$ just indifferent between investing and not investing, it is required that $A$ increases its probability of also investing in loyal customers, because this reduces the expected benefit for $B$ from investing. ${ }^{16}$

Intuitively, investment in citizen loyalty is costly, and its beneficial effect for tax revenues depends on the investment choice of the other country. If both countries do not invest in citizen loyalty, then the tax competition that emerges is very strong and the tax revenue that remains in the equilibrium is zero. Hence, if one country does not invest, the benefit of investing in citizen loyalty is high for the other country, and even the country that does not invest benefits from this investment: the investment makes the countries asymmetric and causes a strategic disadvantage for the country that invested in stage 1 . There is a wide range of parameters in which a country would like to free ride on the loyalty investment made by the other country, and this yields the mixed strategy equilibrium as regards investment in loyalty in stage 1 in which both countries are just indifferent between investing or not, because the respective other country invests with a probability that generates this indifference. If the cost of investment becomes very small, then both countries may prefer to invest. The tax equilibrium in stage 2 is always in mixed strategies. The country that invested in citizen loyalty has a higher expected tax revenue in the equilibrium, and if this difference outweighs the investment cost, both countries prefer the outcome in which they invest in stage 1 . In this outcome both countries compete for the mobile tax base in a mixed strategy equilibrium in stage 2 , but they receive an expected tax revenue that is equal to the stand-alone tax revenue $n r$. Finally, if the cost of making citizens loyal in stage 1 is higher than what can be gained in terms of tax revenue in stage 2 , then both countries abstain from such activities.

The characterization of equilibria also reveals that loyalty investment becomes generally more useful if the set of citizens who can be made loyal by this investment is larger. If some new technology or means of non-price competition affects the size of $n$ positively, this increases the probability for such investment to take place, and also increases the expected tax revenue in the equilibrium. Globalization may affect size of $n$ negatively. This will reduce the probabilities of investment in the mixed strategy equilibrium, and also

\footnotetext{
${ }^{16}$ Note further that the equilibrium probability of investing in citizen loyalty is also decreasing in the cost of such investment for the respective other country. However, this effect is an artefact of the nature of the mixed strategy equilibrium in which the investment probability must be chosen to generate indifference.
} 
reduces the range in which investing is a dominant strategy for countries.

The cost of rent-seeking effort is equal to $c_{A}+c_{B}$ in the equilibrium in which the choice of such effort becomes a dominant strategy, i.e., for $c_{i}<\left[0, \frac{n}{2} n r\right]$ for $i=A, B$. In the coordination equilibrium for $c_{i} \in\left[\frac{n}{2} n r, n r\right]$, the cost of effort is simply $c_{A}$ or $c_{B}$, depending on which of the two equilibria is chosen, and in the mixed strategy equilibrium for this parameter range the expected cost of such effort is

$$
q_{A} c_{A}+q_{B} c_{B}=\frac{2}{(2-n)}\left(c_{A}+c_{B}-\frac{2 c_{A} c_{B}}{n r}\right)
$$

This expected effort is increasing in $n$ and in $r$. This suggests that globalization, interpreted as a decrease in the effectiveness of investment in loyalty, will generally reduce the effort which is invested in such activities. If such efforts are seen as efforts for attracting a larger share in a global common, then this aspect is a beneficial aspect of globalization. However, as a consequence of this reduction in rent-seeking, the tax revenue in the tax competition stage will also fall in expectation, in line with the standard view on globalization and tax competition.

\section{A minimum tax}

Suppose now that countries cannot choose taxes $t_{i}<t_{\text {min }}$ for some exogenous $t_{\min } \cdot{ }^{17}$ If countries anticipate that the tax competition in stage 2 is constrained from below by a minimum tax, this will change the tax competition outcome and also has implications for the choice of the countries' rent-seeking efforts in their investment in loyalty. Proposition 5 considers cases of sufficiently large minimum taxes.

Proposition 5 Let $n_{B}=n_{A}=0$. Any minimum tax $t_{\min }>0$ yields an equilibrium with $t_{A}=t_{B}=t_{\min }$. Let $n_{A}=n_{B}=n$. A minimum tax with $t_{\min } \in[n r, r]$ yields an equilibrium in pure strategies with $t_{A}=t_{B}=t_{\min }$. Let $\min \left\{n_{A}, n_{B}\right\}=0$ and $\max \left\{n_{A}, n_{B}\right\}=n$. Then a minimum tax with $t_{\min } \in\left[\frac{2 r n}{n+2}, r\right]$ yields an equilibrium with $t_{A}=t_{B}=t_{\min }$.

Proof. Consider $n_{A}=n_{B}=0$. Let $A$ choose $t_{A}=t_{\min }>0$. For all $t_{B}>t_{A}$, $B$ will not attract any tax base, and the corresponding tax revenue is zero.

\footnotetext{
${ }^{17}$ For a survey also on the role of minimum taxes and tax harmonization see Fuest, Huber and Mintz (2005), and Peralta and van Ypersele (2006) for a recent contribution.
} 
Accordingly, the optimal reply to $t_{A}=t_{\min }$ is $t_{B}\left(t_{\min }\right)=t_{\min }$, as this yields a tax revenue equal to $t_{\min } \cdot \frac{2}{2}=t_{\min }>0$ for $t_{\text {min }}>0$.

Consider next $n_{A}=n_{B}=n$. Let $A$ choose $t_{A}=t_{\min } \geq n r$. For all $t_{B}>t_{A}$ the country $B$ receives tax revenue $t_{B} n$, which is maximal for $t_{B}=r$. Accordingly, the optimal reply to $t_{A}=t_{\min }$ is either $t_{B}=t_{\min }$ with tax revenue equal to $t_{\min }\left[n+\frac{2-2 n}{2}\right]$ or $t_{B}=r$ with tax revenue equal to $r n$. As the tax revenue $t_{\min } \cdot 1 \geq n r$, the optimal reply is $t_{B}\left(t_{\min }\right)=t_{\min }$. For symmetry, the same condition applies for $t_{A}$ to be an optimal reply to $t_{B}=t_{\min }$.

Consider finally $n_{A}=0$ and $n_{B}=n$. Country $B$ 's optimal reply to $t_{A}=t_{\min } \in\left[\frac{2 r n}{n+2}, r\right]$ is either $t_{B}=r$, yielding tax revenue equal to $r n$, or $t_{B}=t_{\min }$, which yields tax revenue equal to $t_{\min }\left(n+\frac{2-n}{2}\right)$. For $t_{\min }$ to be optimal requires $t_{\min }\left(n+\frac{2-n}{2}\right) \geq r n$, which is equivalent with $t_{\min } \geq \frac{2 r n}{n+2}$. In turn, country $A$ 's optimal reply to $t_{B}=t_{\min }$ is either $t_{\min }$, which yields tax revenue $t_{\min }\left[\frac{2-n}{2}\right]$, or $t_{A}=r$ which yields tax revenue of zero. Accordingly, for $A$ the choice of $t_{A}=t_{\min }>0$ dominates any $t_{A}>t_{B}$ due to $n_{A}=0$. (The same argument holds if the roles of $A$ and $B$ are reversed.)

Proposition 5 characterizes a minimum tax that is so high that the tax revenue that each country has if both charge the minimum tax is higher than what a country can obtain from deviating and choosing any other tax rate higher than this minimum tax. Such a deviation will leave this country with a tax revenue $t_{i} n_{i}$, as the other country receives the tax revenue from its loyal citizens, plus the tax revenue from all mobile citizens. This tax revenue from deviating is therefore maximal if the country $i$ chooses the highest possible tax rate, $r$. The conditions regarding the minimum tax that are stated in Proposition 5 make this tax revenue (weakly) smaller than the tax revenue if the countries both charge the minimum tax.

Note that the imposition of a minimum tax may cause the countries to choose a tax that is lower than the tax they might have chosen otherwise, and the imposition of a minimum tax may cause the expected tax that is charged to reduce. To see this, consider the case with $n_{A}=n_{B}=n$. In this case, without a minimum tax the average tax is

$$
\int_{t=\frac{n r}{2-n}}^{r} F^{\prime}(t) t d t=\frac{1}{2} \frac{r n}{(1-n)}\left(\ln (r)-\ln \left(\frac{n r}{2-n}\right)\right),
$$

with $F^{\prime}(t)$ calculated from (3) for $n_{A}=n_{B}=n$. This average tax rate without a minimum tax is higher than the equilibrium tax with a minimum tax equal to $t_{\min }=n r$ if 


$$
\frac{1}{2} \frac{r n}{(1-n)}\left(\ln (r)-\ln \left(\frac{n r}{2-n}\right)\right)-n r>0,
$$

which is equivalent with $\frac{2-n}{n}>\exp (2-2 n)$ and holds for $n \in(0,1)$. The coordinated minimum tax (and even a high one) can drive down the average tax rate. Note that this does not imply that the minimum tax also drives down the average tax revenue, as the mobile tax base always moves to the low-tax country. Hence, the average tax burden on tax base is lower in the equilibrium with the unconstrained tax rate than the average tax rate.

Turning next to the implications of a sufficiently high minimum tax for the choices of $n_{A}$ and $n_{B}$, the following proposition holds:

Proposition 6 If the minimum tax is $t_{\min } \geq n r$ then a subgame perfect equilibrium exists with country $i$ choosing

$$
n_{i}=\left\{\begin{array}{cl}
n & \text { if } \quad t_{\min } \frac{n}{2}>c_{i} \\
0 & \text { if } t_{\min } \frac{n}{2} \leq c_{i}
\end{array}\right.
$$

Proof. Both countries anticipate that $t_{A}=t_{B}=t_{\text {min }}$. Accordingly, the payoff of country $A$ is $t_{\min } \frac{2-n_{B}}{2}$ if $n_{A}=0$, and equal to $t_{\min } \frac{2-n_{A}-n_{B}}{2}+t_{\min } n_{A}-$ $c_{A}$ if $n_{A}=n$, and similarly for $B$. The optimality of $n_{i}$ as characterized in the proposition follows from comparing these payoffs.

Note that $n r \geq \frac{2 r n}{n+2}$. The minimum tax $t_{\min } \geq n r$ is, therefore, sufficiently high such that the equilibrium tax is $t_{\min }$ for all combinations of loyalty investment in stage 1 . Indeed, as this is not true for the $t_{\min } \in\left[\frac{2 r n}{n+2}, n r\right]$ this parameter range is more cumbersome and not treated formally here.

Intuitively, if the minimum tax rate is sufficiently high, both countries choose a tax rate equal to this minimum tax rate in the stage-2 equilibrium. As they can charge this tax rate on all their loyal citizens, but have to share the mobile citizens with the other country, the investment in loyalty of a set of $n$ citizens is worthwhile if the cost of this investment is lower than the additional tax revenue that results from this investment, which is equal to $t_{\min } n / 2$. A sufficiently high minimum tax turns the problem in a pure common pool problem: the common pool is shared equally between the competitors, unless they expend effort trying to appropriate a larger share of the common pool for themselves. This is what is accomplished by the investment in loyalty. 
Cases with a lower minimum tax rate yield a more colorful picture. The way the taxation equilibrium is affected by the minimum tax depends on the choices $\left(n_{A}, n_{B}\right)$. Three cases need to be distinguished.

Case 1: $n_{A}=n_{B}=0$. In this case any positive minimum tax leads to a tax equilibrium with $t_{A}=t_{B}=t_{\min } \leq r n$ and tax revenues $T_{A}\left(t_{\min }\right)=$ $T_{B}\left(t_{\min }\right)=t_{\min }$.

Case 2: $n_{A}=n_{B}=n$. If $t_{\min } \leq n r /(2-n)$, then the equilibrium tax strategies as in Section 2 are still feasible and mutually optimal replies. Hence, the tax equilibrium is unaffected. If $t_{\min } \in\left(\frac{n r}{2-n}, r n\right)$, then the equilibrium is in mixed strategies, with the cdfs of tax rates that are characterized by Figure 2 being optimal replies to each other. This mutual optimality can be checked as follows. First we observe that, given $F_{B}$ as in Figure 2, the expected tax revenue of country $A$ is equal to $n r$ for all $t_{A} \in\left\{t_{\min }\right\} \cup\left[t_{0}, r\right]$ by inserting in the payoff functions, taking into consideration that $t_{0}=\frac{n r t_{\min }}{n t_{\min }-2 t_{\min }+2 n r}$.

Intuitively, $A$ 's payoff along the interval $t_{A} \in\left(t_{0}, r\right)$ is the same as in the absence of a minimum tax. However, once the tax rate which $A$ may choose drops further and comes sufficiently close to the minimum tax, the minimum tax becomes more attractive than this tax: unlike without this minimum tax, $A$ cannot be undercut at the minimum tax. Both players have a mass point at the minimum tax. In turn, this implies that, if they both choose the minimum tax, they have to share the mobile tax base equally. If $A$ increases $t_{A}$ just slightly above $t_{\min }$, this increases $A$ 's tax revenue on $n_{A}=n$, but $A$ loses the tax revenue on $\frac{2-2 n}{2} F_{B}\left(t_{\min }\right)$ as all the mobile tax base stays with $B$ with probability $F_{B}\left(t_{\min }\right)$. Hence, small increases in $t_{A}$ compared to $t_{A}=t_{\min }$ are inferior. Only if $A$ chooses a sufficiently high tax rate, the gain on the loyal tax payers compensates for this expected loss in the mobile tax base. The tax rate $t_{0}$ and the mass point it generates at $t_{\min }$ just balance in the sense that the payoff from choosing $t_{0}$ (or any other $t_{A} \in\left(t_{0}, r\right)$ ) is equal to the payoff from choosing $t_{\min }$.

By symmetry, the same reasoning applies for $B$. Third, note that any feasible choices of $t_{A}$ or $t_{B}$ from $\left(t_{\min }, t_{0}\right)$ outside the equilibriums support, yield lower tax revenue.

The expected tax revenue of each country in this equilibrium is $T_{A}=$ $T_{B}=n r$, and the size of the mass point at $t_{\min }$ is obtained from inserting $t_{0}$ into the cdf:

$$
F_{i}\left(t_{0}\right)=1+\frac{n}{2-2 n}-\frac{n r}{(2-2 n) t_{0}}=\frac{(2-n) t_{\min }-n r}{(1-n) t_{\min }} .
$$




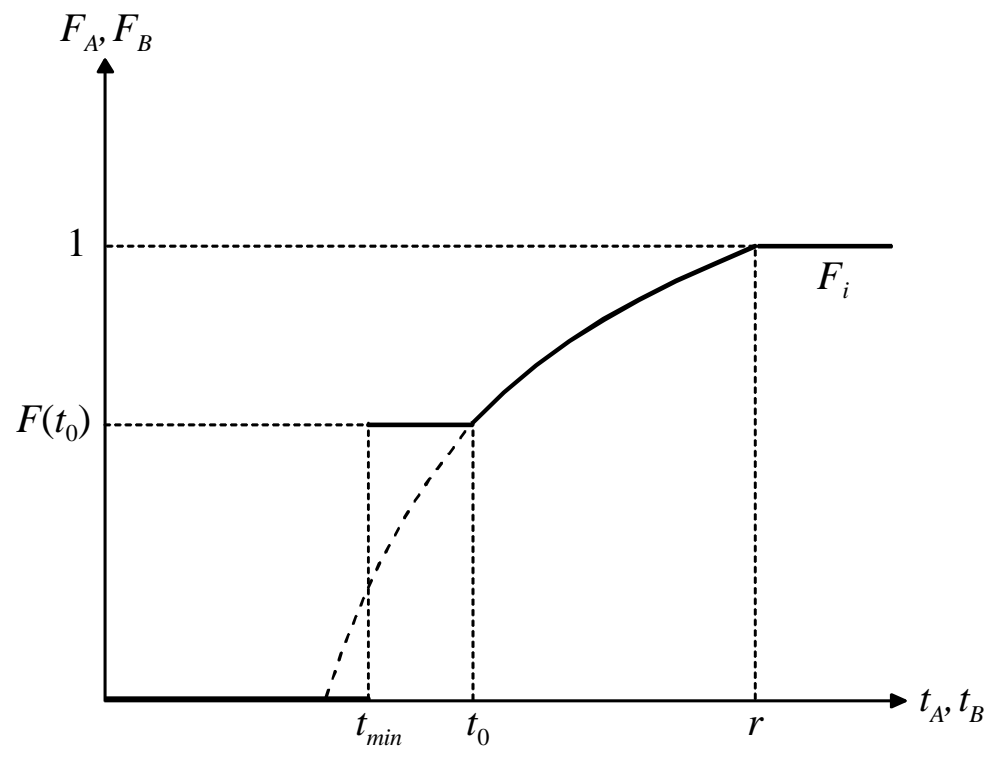

Figure 2: The equilibrium cdfs for $n_{A}=n_{B}=n$ and $t_{\min } \in\left(\frac{n r}{2-n}, r n\right)$ for numerical values $n=.5, r=1$ and $t_{\min }=.4$.

Case 3: $n_{A}=0, n_{B}=n$. (Note that there is also an antisymmetric Case 4 which is obtained from Case 3 by $A$ and $B$ changing roles). If $t_{\min } \leq$ $n r / 2$, then the equilibrium tax strategies as in Section 2 are still feasible and mutually optimal replies. Hence, the tax equilibrium is unaffected. If $t_{\text {min }} \in$ $\left(\frac{n r}{2}, \frac{2 r n}{n+2}\right)$, then the equilibrium is in mixed strategies in tax rate choices, with the cdfs that are characterized in Figure 3, with $t_{0}=\frac{n r t_{\min }}{2\left(n r-t_{\min }\right)}$. These cdfs coincide with the equilibrium mixed strategies in the case without a minimum tax in the range $t_{i} \in\left(t_{0}, r\right)$. However, both players have a mass point at the minimum tax and do not choose taxes in the range $\left(t_{\min }, t_{0}\right)$. The mutual optimality of these strategies can be confirmed as follows: first, it can be verified by inserting into the equation that determines $A$ 's expected tax revenue for given $F_{B}(t)$, that the expected tax revenue for country $A$ is equal to $\frac{n r}{2}(2-n)$ for any choice $t_{A} \in\left\{t_{\min }\right\} \cup\left[t_{0}, r\right]$, and strictly lower for any feasible $t_{A}$ from outside this set. Second, it can be verified by inserting into the equation that determines $B$ 's expected tax revenue for given $F_{A}(t)$, that the expected tax revenue for $B$ is equal to $n r$ for any choice $t_{B} \in$ $\left\{t_{\min }\right\} \cup\left[t_{0}, r\right]$, and strictly lower for any feasible $t_{B}$ from outside this set. 


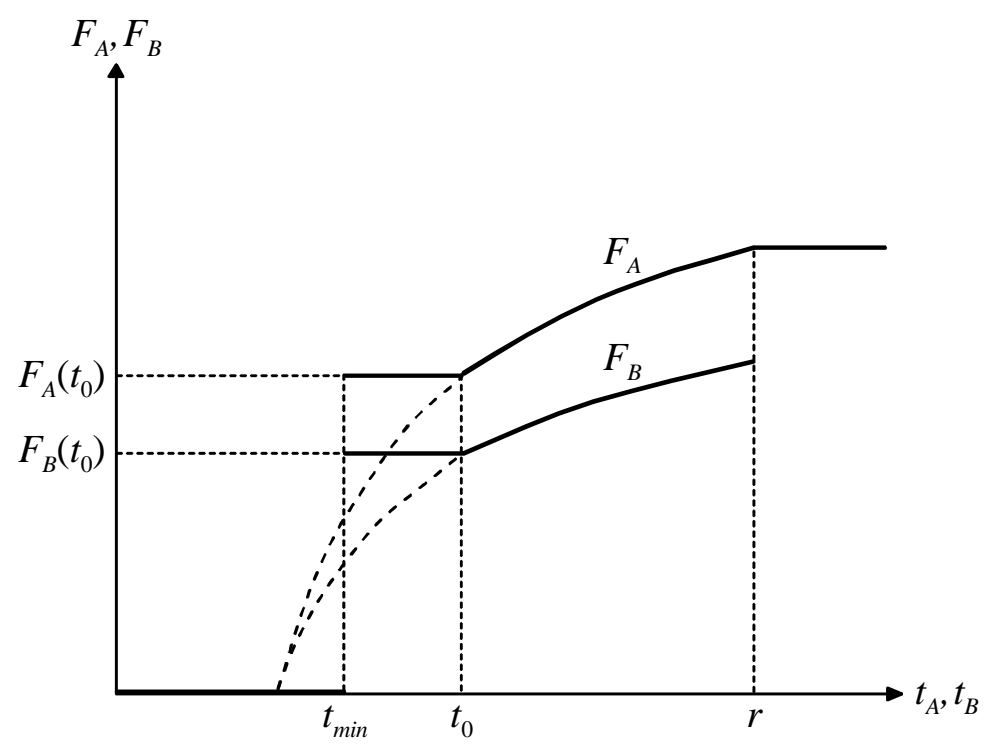

Figure 3: The equilibrium cdfs for $n_{A}=0, n_{B}=n$ and $t_{\min } \in\left(\frac{n r}{2}, \frac{2 r n}{n+2}\right)$ for numerical values $n=.5, r=1$ and $t_{\min }=.4$.

The mixed strategy equilibrium that emerges for the intermediate range of minimum taxes is structurally similar to the mixed strategy equilibrium that emerges in all-pay auctions if players face an upper limit on their individual bidding efforts. The latter problem has been studied by Che and Gale (1998). This equilibrium is generically unique, but for some particular combinations of parameters further equilibria can emerge.

Consider now the choice of investment in citizens' loyalty in stage 1 . Recall that $\frac{2 r n}{n+2} \leq n r$. Accordingly, for the range $t_{\min }<\frac{2 r n}{n+2}$ the following equilibrium payoffs emerge from the different investment choices according to the three cases that have been outlined:

\begin{tabular}{|c|c|c|}
\hline & $n_{B}=0$ & $n_{B}=n$ \\
\hline$n_{A}=0$ & $\pi_{A}=t_{\min }$ & $\pi_{A}=\frac{2-n}{2} n r$ \\
& $\pi_{B}=t_{\min }$ & $\pi_{B}=n r-c_{B}$ \\
\hline$n_{A}=n$ & $\pi_{A}=n r-c_{A}$ & $\pi_{A}=n r-c_{A}$ \\
& $\pi_{B}=\frac{2-n}{2} n r$ & $\pi_{B}=n r-c_{B}$ \\
\hline
\end{tabular}


The equilibrium choices of investment can be inferred from this matrix along similar lines as in the case without a minimum tax. The optimal investment reply of country $i$ anticipating equilibrium play in stage 2 depends on $q_{j}, t_{\text {min }}$ and $c_{i}$ :

$$
n_{i}=\left\{\begin{array}{lll}
0 & \text { if } & q_{j} \frac{2-n}{2} n r+\left(1-q_{j}\right) t_{\min }>n r-c_{i} \\
n & \text { if } & q_{j} \frac{2-n}{2} n r+\left(1-q_{j}\right) t_{\min }<n r-c_{i}
\end{array}\right.
$$

and any $q_{i} \in[0,1]$ is optimal if $q_{j} \frac{2-n}{2} n r+\left(1-q_{j}\right) t_{\min }=n r-c_{i}$. This leads to the following

Proposition 7 (i) The introduction of a minimum tax $t_{\min }<\frac{2 r n}{n+2}$ increases the range of investment cost for which $n_{i}=0$ is a dominant strategy. (ii) The minimum tax decreases the range of a country's cost in which $n_{i}=n$ is a dominant strategy. (iii) The minimum tax does not affect country i's equilibrium payoff if $q_{i}>0$ in the equilibrium.

Proof. (i): By (13) the choice $n_{i}=0$ is a dominant strategy for $i$ if $c_{i}>$ $n r-q_{j} \frac{2-n}{2} n r+\left(1-q_{j}\right) t_{\min }$ for all $q_{j} \in[0,1]$. The right-hand side of this inequality is strictly increasing in $t_{\min }$ for any given $q_{j}<1$ and constant in $t_{\text {min }}$ for $q_{j}=1$. (ii): By (13) the choice $n_{i}=1$ is a dominant strategy for $i$ if $c_{i}<n r-q_{j} \frac{2-n}{2} n r+\left(1-q_{j}\right) t_{\min }$ for all $q_{j} \in[0,1]$. The right-hand side of this inequality is strictly increasing for all $q_{j}<1$ and constant in $t_{\text {min }}$ for $q_{j}=1$. (iii) If $q_{i}>0$, then $n_{i}=n$ is an optimal investment choice and leads to a payoff equal to $n r-c_{i}$, which is independent of $t_{\min }$.

A minimum tax increases the payoffs of the two countries in case they both do not invest, but does not affect the payoffs if at least one of the countries invests. The immediate effect of this is that investment in loyalty of citizens becomes less rewarding. A low minimum tax may therefore have no impact on the actual tax competition in case at least one country invested in loyal citizens, but it may reduce the incentives to invest in loyalty. For some range of parameters, a small coordinated minimum tax can therefore reduce the efforts that countries expend in establishing property rights in their citizens or tax payers.

\section{A harmonized tax}

Tax harmonization is among the proposals considered by policy makers in the context of tax competition. Some degree of harmonization has been 
reached, for instance, within the European Union, with respect to import duties. Harmonization is also discussed frequently in the context of corporate taxation. For instance, the Ruding committee (CEC 1992) has made explicit recommendations in this respect. The benefits and costs of tax harmonization have also stimulated considerable interest in the academic literature on tax competition. It has been noticed that harmonization of taxes is often partial in the sense that, while it blocks tax competition with respect to some tax instruments, there remains a sufficient number of other instruments that allow for tax competition to continue. ${ }^{18}$ The analysis here follows a similar line of argument. Tax harmonization will not remove or block the non-price competition instruments available to countries.

The case with perfect tax harmonization turns the competition problem between countries into a pure common-pool problem. The countries will try to acquire a high share in the tax base and then tax it according to the rate they have agreed upon.

Consider non-price competition, assuming that the tax rate that is chosen by both countries is uniform and equal to $t^{h}$. The following proposition describes the equilibrium in stage 1.

Proposition 8 If $\frac{1}{2} t^{h} n \geq \max \left\{c_{A}, c_{B}\right\}$ then both countries invest in home attachment of their citizens. If $\min \left\{c_{A}, c_{B}\right\}<\frac{1}{2} t^{h} n<\max \left\{c_{A}, c_{B}\right\}$ then only the country with the smaller cost invests. If $\min \left\{c_{A}, c_{B}\right\}>\frac{1}{2} t^{h} n$ then none of the countries invests in the home attachment of their citizens.

Proof. For a proof, note that the payoffs from different investment strategies are as in the following payoff matrix:

\begin{tabular}{|c|c|c|}
\hline & $n_{B}=0$ & $n_{B}=n$ \\
\hline$n_{A}=0$ & $\pi_{A}=t^{h}$ & $\pi_{A}=\frac{2-n}{2} t^{h}$ \\
& $\pi_{B}=t^{h}$ & $\pi_{B}=\frac{1}{2} n t^{h}+t^{h}-c_{B}$ \\
\hline$n_{A}=n$ & $\pi_{A}=\frac{1}{2} n t^{h}+t^{h}-c_{A}$ & $\pi_{A}=t^{h}-c_{A}$ \\
& $\pi_{B}=\frac{2-n}{2} t^{h}$ & $\pi_{B}=t^{h}-c_{B}$ \\
\hline
\end{tabular}

Let $c_{A} \geq c_{B}$. Then the equilibrium is in pure strategies with $n_{A}=n_{B}=n$ if $c_{B} \leq c_{A} \leq \frac{1}{2} t^{h} n$, as this implies that both players prefer to invest, regardless

\footnotetext{
${ }^{18}$ See, e.g., Fuest (1995), Fuest and Huber (1999), Marchand, Pestieau and Sato (2003), and Wehke (2006).
} 
whether the other player invested or not. Second, if $c_{B}<\frac{1}{2} t^{h} n<c_{A}$, then an equilibrium exists in which only $B$ invests and $A$ prefers not to invest. This can also be seen from the matrix in (14): $B$ prefers to invest, as the additional profit from investing is $\frac{1}{2} t^{h} n-c_{B}>0$, independent of whether $A$ invests or not, and for $A$ the cost of investing exceeds the benefits in terms of additional tax returns, independent of whether $B$ invests or not. Hence, this asymmetric equilibrium is an equilibrium in dominant strategies. Finally, if $c_{A} \geq c_{B}>\frac{1}{2} t^{h} n$, then both players prefer not to invest, independent of the other player's investment decision.

Overall, Proposition 8 shows that there are threshold levels for the harmonized tax rate. If the harmonized tax rate is very low, this low level of the tax removes the incentives to generate home-attachment. If the tax rate is above some level, at least one of the countries starts to invest, and if the tax rate is sufficiently high, both countries prefer investment compared to the option not to invest. This structure is equivalent to a most simple version of a rentseeking contest. It is, however, a rent-seeking contest in which investment effort can take only a discrete number of levels, and the contest is initiated only if what can be gained from expending contest effort is sufficiently much. The outcome with both countries investing in home attachment of their citizens constitutes the classical symmetric prisoners' dilemma in which both sides expend appropriation effort, without winning anything in addition in the aggregate. Both players expend effort to define "property rights" in part of this tax base, i.e., to protect part of their home tax base from possibly floating out of the country.

\section{Conclusions}

In a globalized economy with vanishing physical cost of crossing borders for human capital, financial capital and direct investment, the stock of mobile capital can be seen as a global common: all countries would like to graze on this common: they would like to attract a large share of this capital and levy taxes on it or its returns. Unfortunately capital is a shy species, and has a tendency to flee from high-tax countries to low-tax countries. This relationship has studied intensively in the context of the tax competition literature.

The common resource property aspect of the global tax base becomes visible from observing that competition for capital is not only fiscal com- 
petition. Countries use other activities to generate a favorable bias that relaxes Bertrand competition. The activities include informative or persuasive advertising, political persuasion and influence, and effort that increases the value of the brand name of a country and enables policies that make investors or citizens loyal to this brand. These include educational effort that generates home attachment or even patriotism among the own population. This rent-seeking competition closely resembles the competition for a common pool resource in which players expend effort trying to acquire property rights in, or a share of, a common pool resource.

Bertrand competition in tax rates interacts with the appropriation conflict in which countries fight about property rights in the tax base. In the formal part of the paper I assumed that countries can generate loyalty of some group of capital owners by expending appropriate effort. I then considered the outcome of tax competition in a framework in which some or all countries induced loyalty among a subgroup of their citizens. Based on this tax competition outcome I analyze the incentives for such loyalty investment. Countries with low cost of such investment have a higher incentive to invest in the loyalty of their own citizens, but higher loyalty among own citizens is a strategic disadvantage in the tax competition game.

I also consider tax harmonization and tax coordination (a minimum tax) and show that such measures have a tendency to reduce the incentives to engage in appropriation effort.

The welfare implications of this analysis are difficult, given that home attachment often goes along with a change in the preferences of citizens. As far as home attachment is simply a means to increase the mobility cost to a prohibitively high level, the investment in such citizen loyalty is wasteful from a global point of view. However, in a second-best world such investment may be beneficial as it allows countries to collect higher tax returns from their citizens in the Bertrand equilibrium. Where the erosion of tax revenue endangers the welfare state, these activities can be seen as secondbest reactions of the nation states by which they address the problem of eroding tax revenues.

\section{References}

[1] Andersson, Fredrik, and Kai A. Konrad, 2003, Human capital investment and globalization in extortionary states, Journal of Public Eco- 
nomics, 87 (7-8), 1539-1555.

[2] Baye, Michael R., Dan Kovenock, and Casper de Vries, 1992, It takes two to tango: equilibria in a model of sales, Games and Economic Behavior, 4 (4), 493-510.

[3] Baye, Michael R., John Morgan, and Patrick Scholten, 2007, Information, search, and price dispersion, in: Terrence Hendershott (ed.), Handbook on Economics and Information Systems, Elsevier, Amsterdam (forthcoming).

[4] Besley, Timothy, and Paul Seabright, 1999, The effects and policy implications of state aids to industry: an economic analysis, Economic Policy, 14 (28), 13-53.

[5] Bhagwati, Jagdish, 1976, The brain drain, International Social Science Journal, 28 (4), 691-729.

[6] Bhagwati, Jagdish, and William Dellalfar, 1973, The brain drain and income taxation, World Development, 1 (1-2), 94-101.

[7] Black, Dan A., and William H. Hoyt , 1989, Bidding for firms, American Economic Review, 79(5), 1249-1256.

[8] Benassy-Quere, Agnes, Nicolas Gobalraja, and Alain Trannoy, 2007, Tax and public input competition, Economic Policy, 22 (50), 385-430.

[9] Bucovetsky, Sam, 2005, Public input competition, Journal of Public Economics, 89 (9-10), 1763-1787.

[10] CEC, 1992, Report of the Committee of Independent Experts on Company Taxation, Commission of the European Communities, Luxembourg, Office of the Official Publications of the EC.

[11] Che, Yeon-Koo, and Ian L. Gale, 1998, Caps on political lobbying, American Economic Review, 88 (3), 643-651.

[12] De Mooij, Ruud A., and Sjef Ederveen, 2003, Taxation and foreign direct investment: a synthesis of empirical research, International Tax and Public Finance, 10 (6), 673-693.

[13] Deneckere, Raymond J., Dan Kovenock, and Robert Lee, 1992, A model of price leadership based on consumer loyalty, Journal of Industrial Economics, 40 (2), 147-156. 
[14] Devereux, Michael P., Rachel Griffith, and Alexander Klemm, 2002, Corporate income tax reforms and international tax competition, Economic Policy, 17 (35), 449-495.

[15] Devereux, Michael P., Ben Lockwood, and Michaela Redoano, 2002, Do Countries Compete over Corporate Tax Rates? CEPR Discussion Paper No. 3400.

[16] Friedman, Lawrence, 1958, Game-theory models in the allocation of advertising expenditures, Operations Research, 6 (5), 699-709.

[17] Fuest, Clemens, 1995, Interjurisdictional competition and public expenditure: is tax co-ordination counterproductive? Finanzarchiv, N.F. 52 (4), 478-496.

[18] Fuest, Clemens, and Bernd Huber, 1999, Can tax coordination work? Finanzarchiv, N.F. 56 (3-4), 443-458.

[19] Fuest, Clemens, Bernd Huber and Jack Mintz, 2005, Capital Mobility and Tax Competition, Foundations and Trends in Microeconomics, 1 (1), 1-62.

[20] Gordon, Roger H., 1986, Taxation of investment and savings in a world economy, American Economic Review, 76 (5), 1086-1102.

[21] Gordon, Roger H., 1992, Can capital income taxes survive in open economies? Journal of Finance, 47 (3), 1159-1180.

[22] Hadar, Josef, and William R. Russell, 1969, Rules for ordering uncertain prospects, American Economic Review, 59 (1), 25-34.

[23] Hartman, David G., 1984, Tax policy and foreign direct investment in the United States, National Tax Journal, 37 (4), 475-487.

[24] Hohaus, Bolko, Kai A. Konrad, and Marcel Thum, 1994, Too much conformity - a Hotelling model of local public goods supply, Economics Letters, 44 (3), 295-299.

[25] Jayet, Hubert, and Sonia Paty, 2006, Capital indivisibility and tax competition: Are there too many business areas when some of them are empty? Journal of Urban Economics, 60 (3), 399-417.

[26] Justman, Moshe, Thisse Jaques-François, and Tanguy van Ypersele, 2002, Taking the bite out of fiscal competition, Journal of Urban Economics, 52 (2), 294-315. 
[27] Justman, Moshe, Thisse Jaques-François, and Tanguy van Ypersele, 2005, Fiscal competition and regional differentiation, Regional Science and Urban Economics, 35 (6), 848-861.

[28] Keen, Michael J., 1998, Vertical tax externalities in the theory of fiscal federalism, IMF Staff Papers, 45 (3), 454-485.

[29] Keen, Michael J., and Christos Kotsogiannis, 2002, Does federalism lead to excessively high taxes?, American Economic Review, 92 (1), 363370.

[30] Keen, Michael J., and Maurice Marchand, 1997, Fiscal competition and the pattern of public spending, Journal of Public Economics, 66 (1): $33-53$.

[31] Kessing, Sebastian, and Kai A. Konrad, 2007, Patriotism and taxation, unpublished manuscript.

[32] Kind, Hans J., Karen H. M. Knarvik, and Guttorm Schjelderup, 2000, Competing for capital in a 'lumpy' world, Journal of Public Economics, 78 (3), 253-274.

[33] Mansoorian, Arman, and Gordon M. Myers, 1993, Attachment to home and efficient purchases of population in a fiscal externality economy, Journal of Public Economics, 52(1), 117-132.

[34] Marchand, Maurice, Pierre Pestieau, and Motohiro Sato, 2003, Can partial fiscal coordination be welfare worsening? A model of tax competition, Journal of Urban Economics, 54 (3), 451-458.

[35] Matsumoto, Mutsumi, 2000, A note on the composition of public expenditure under capital tax competition, International Tax and Public Finance, 7 (6), 691-697.

[36] Matsumoto, Mutsumi, 2004, The mix of public inputs under tax competition, Journal of Urban Economics, 56 (2), 389-396.

[37] Menezes, Flavio M., 2003, An auction theoretical approach to fiscal wars, Social Choice and Welfare, 20 (1), 155-166.

[38] Narasimhan, Chakravarthi, 1988, Competitive promotional strategies, Journal of Business, 61 (4), 427-449.

[39] Ogura, Laudo M., 2006, A note on tax competition, attachment to home, and underprovision of public goods, Journal of Urban Economics, 59 (2), 252-258. 
[40] Peralta, Susana, and Tanguy van Ypersele, 2006, Coordination of capital taxation among asymmetric countries, Regional Science and Urban Economics, 36(6), 708-726.

[41] Raymond, Richard, 1973, The interregional brain drain and public education, Growth and Change, 4 (3), 28-34.

[42] Rose, Andrew K., 2007, The foreign service and foreign trade: embassies as export promotion, World Economy, 30 (1), 22-38.

[43] Roy, Santanu, 2000, Strategic segmentation of a market, International Journal of Industrial Organization, 18 (8), 1279-1290.

[44] Schmalensee, Richard, 1976, A model of promotional competition in oligopoly, Review of Economic Studies, 43 (3), 493-507.

[45] Sinn, Hans-Werner, 1990, Tax harmonization and tax competition in Europe, European Economic Review, 34 (2-3), 489-504.

[46] Sinn, Hans-Werner, 1997, The selection principle and market failure in systems competition, Journal of Public Economics, 66 (2), 247-274.

[47] Sørensen, Peter Birch, 2007, Can capital income taxes survive? And should they?, CESifo Economic Studies, 53 (2), 172-228.

[48] Stewart, Kenneth, and Michael Webb, 2006, International competition in corporate taxation: evidence from the OECD time series, Economic Policy, 21 (45), 153-201.

[49] Taylor, Leon, 1992, Infrastructural competition among jurisdictions, Journal of Public Economics, 49 (2), 241-259.

[50] Varian, Hal, 1980, A model of sales, American Economic Review, 70 (4), 651-659.

[51] Wehke, Sven, 2006, Tax competition and partial coordination, Finanzarchiv 62 (3), 416-436.

[52] Wildasin, David E., 1988, Nash equilibria in models of fiscal competition, Journal of Public Economics, 35 (2), 229-240.

[53] Wildasin, David E., 1991, Some rudimetary 'duopolity' theory, Regional Science and Urban Economics, 21 (3), 393-421.

[54] Wildasin, David E., and John D. Wilson, 2004, Capital tax competition: bane or boon, Journal of Public Economics, 88 (6), 1065-1091. 
[55] Wilson, John D., 1986, A theory of interregional tax competition, Journal of Urban Economics, 19 (3), 296-315.

[56] Wilson, John D., 1999, Theories of tax competition, National Tax Journal, 52 (2), 269-304.

[57] Wilson, John D., 2005, Welfare-improving competition for mobile capital, Journal of Urban Economics, 57 (1), 1-18.

[58] Wrede, Matthias, 1997, Tax competition and federalism: The underprovision of local public goods, FinanzArchiv, N.F. 54 (4), 494-515.

[59] Wrede, Matthias, 1999, Tragedy of the fiscal common?: Fiscal stock externalties in a leviathan model of federalism, Public Choice, 101 (3-4), 177-193.

[60] Wrede, Matthias, 2000, Shared tax sources and public expenditures, International Tax and Public Finance, 7 (2), 163-175.

[61] Zodrow, George R., and Peter Mieszkowski, 1986, Pigou, Tiebout, property taxation, and the underprovision of local public goods, Journal of Urban Economics, 19 (3), 356-370. 